\title{
AVALIAÇÃO SENSORIAL DE CEREAIS MATINAIS DE CASTANHA-DO-BRASIL COM MANDIOCA EXTRUSADOS ${ }^{1}$
}

\author{
Maria Luzenira de SOUZA ${ }^{2, *}$, Hilary Castle de MENEZES ${ }^{3}$
}

\begin{abstract}
RESUMO
Este trabalho objetivou estudar a aceitabilidade de cereais matinais de torta de amêndoa de castanha-do-brasil com mandioca extrusados nos sabores doce, salgado e natural, referentes aos atributos: aceitação global, sabor, crocância e intenção de compra por 06 meses de armazenagem à temperatura ambiente de Campinas-SP. As amostras foram servidas a um painel constituído por 40 consumidores, de forma balanceada em pratos pretos codificados com três dígitos e os resultados, comparados com um produto similar disponível no mercado. Os resultados mostraram que os três tipos de cereais matinais de castanha-do-brasil com mandioca alcançaram maiores notas para todas os atributos sensoriais avaliados do que o cereal matinal similar comercializado, com diferenças significativas $(\leq 0,05)$ pelo teste de Tukey. O mesmo teste mostrou que a crocância do cereal de castanha-do-brasil com mandioca sabor doce foi diferente ( $\mathrm{p} \leq 0,05$ ), no segundo, terceiro e sexto mês de armazenagem, das médias dos de sabores natural e salgado, cuja média das notas do cereal doce foi superior; as demais não diferiram. Dos três cereais matinais estudados o de sabor doce recebeu as maiores notas para todos os atributos avaliados, porém com diferença significativa para alguns parâmetros e tempos de estocagem. Em relação aos atributos avaliação global, sabor e crocância, os cereais de castanha com mandioca tiveram notas equivalendo a gostei muito e gostei moderadamente, enquanto o produto comercial obteve notas equivalendo a nem gostei nem desgostei para os dois primeiros atributos e gostei ligeiramente para crocância. Na intenção de compra, os produtos processados receberam notas equivalendo a possivelmente compraria e o cereal comercial talvez comprasse/talvez não comprasse.

Palavras-chave: cereal matinal extrusado, castanha-do-brasil com mandioca, crocância, sabor, aceitação.
\end{abstract}

\section{SUMMARY}

SENSORIAL EVALUATION OF MATUTINAL CEREALS OF THE BRAZIL NUT WITH EXTRUDED CASSAVA. The aim of this work is to study the acceptability of matutinal cereals of almond pie of the Brazil nut with cassava extruded with sweet, savoury and natural flavors regarding the following attributes: global acceptance, flavor, crispness and purchase intention for a six month product stored at the temperature it sets. The samples were served in a balanced way to a panel of 40 consumers on black plates, coded with three digits and compared with the results of a similar product available on the market. The three kinds of matutinal cereals of Brazil nut with cassava obtained larger scores in all the appraised sensorial characteristics than the matutinal cereal commercialized on the market, presenting a significant difference $(\leq 0.05)$ for the Tukey test. The same test showed that the crispness of the cereal containing the Brazil nut with cassava and a sweet flavor was different ( $p \leq 0.05)$ in the second, third and sixth month of storage of the averages of natural and savoury flavors while the other did not differ. Among the tree flavors of cereals, the sweet one obtained the highest scores in all evaluating attributes, however with a significant difference for some parameters and storage time. Regarding the attributes: global acceptance, flavor and crispness, the Brazil nut cereals and cassava obtained the following results: "I liked it very much" and "I liked it moderately", while the similar commercialized product obtained the following results: "indifferent to the flavor" for the two first attributes and "I liked it a little" for the crispness. For the purpose of purchasing, the processed products of Brazil nut and cassava obtained the following results: "I would possibly buy it" while the commercialized one obtained "maybe I would buy it or maybe not".

Keywords: cereals of almond pie of Brazil nut with extruded cassava, crispness, flavor, acceptance.

\section{1 - INTRODUÇÃO}

Cereais matinais são produtos extrusados, tradicionalmente consumidos com leite e o principal componente é o amido. A característica de crocância destes produtos está

\footnotetext{
${ }^{1}$ Recebido para publicação em 19/7/2006. Aceito para publicação em 20/10/2006 (001799)

${ }^{2}$ Unidade de Tecnologia de Alimentos (UTAL),

Departamento de Ciências Agrárias, (DCA)

Universidade Federal do Acre, (UFAC), Campus Universitário,

BR 364, Km 4, CEP 69915-900, Rio Branco, (AC), Brasil

E-mails:luzenira@ufac.br,mluzen@hotmail.com

${ }^{3}$ Universidade Estadual de Campinas, (UNICAMP),

Faculdade de Engenharia de Alimentos, (FEA),

Departamento de Tecnologia de Alimentos, (DTA),

Rua Monteiro Lobato, 80, Barão Geraldo, C. P. 6121,

CEP 13083-970, Campinas, (SP), Brasil

E-mail: hilary@fea.unicamp.br

* A quem a correspondência deve ser enviada
}

associada ao frescor e qualidade do produto e a sua perda é uma das causas de rejeição de consumo [26]. Esses produtos já alcançam algumas décadas de existência no mercado e o seu consumo vêm ao encontro das novas tendências alimentares, assumindo o lugar de produtos energéticos, protéicos, nutritivos, práticos e saudáveis.

Os corn-flakes são os grandes precursores de uma vasta diversidade que hoje invade as prateleiras dos supermercados. O processo de extrusão de farinhas permite desenvolver várias formas de cereais matinais com diversos formatos como: bolinha, estrela, lua, concha, outros, diferentes tamanhos, cores e sabores, destinados aos mais variados consumidores [18].

A combinação de sabor agradável e elevado valor nutricional produz inúmeros snacks e cereais processados que são sucesso entre os consumidores, desde que contenha ingredientes naturais como nozes, frutas e cereais [15]. 
Cozimento por extrusão tem sido usado por processadores de alimentos há muitos anos. Produtos alimentícios dos tipos cereais prontos para consumo, como snacks, cereais matinais, produtos de confeitaria e de macarrão e produtos de proteína texturizada de soja podem ser obtidos com a tecnologia de extrusão [10, 25]. Para aumentar o teor de proteína e melhorar o valor nutritivo dos produtos extrusados, várias fontes de proteínas, tais como de amendoim, glúten de trigo, milho, aveia, soja e outros podem ser utilizadas nas formulações de produtos processados por extrusão [3, 25]. O enriquecimento deste tipo de alimento é de grande interesse do público que busca produtos alimentícios mais nutritivos, que garantam uma ingestão diária adequada de nutrientes, seja para a otimização, o crescimento e desenvolvimento de crianças e adolescentes, seja para a manutenção da saúde de adultos.

Muitas pesquisas têm revelado os efeitos benéficos de determinados componentes dos alimentos para a saúde, os chamados alimentos e ingredientes funcionais. Assim, aumentou o número de consumidores interessados no papel de alimentos específicos ou componentes alimentares fisiologicamente ativos, os alimentos funcionais que melhoram a saúde [7].

O consumo de cereais integrais como grãos e farinhas mais grossas apresenta uma relação direta com o aumento do peristaltismo, exercitando os movimentos do sistema digestivo [13]. Quando se busca um produto caseiro, a seleção da matéria-prima e a formulação podem atender ao gosto, à necessidade do consumidor e aos fatores sensoriais de aceitabilidade do produto [19].

ALVAREZ et al. [1] argumentam que os alimentos são consumidos não só pelo valor nutricional, mas também pela satisfação e prazer em se alimentar. As sensações experimentadas como deformação e fratura da matriz alimento, durante os estágios iniciais de mordida e mastigação, determinam e/ou influenciam na aceitação ou rejeição pelo produto. Textura crocante (crispness) é definida por muitos autores como a característica exibida pela firmeza do material que demonstra comportamento linear elástico de ruptura.

ORAM [14] afirma que as pessoas quando consomem determinado alimento, sentem muitas características de textura. Tal atributo inclui propriedades mecânicas, geométricas, de composição, temperatura e viscosidade. Atributos químicos também produzem sensações, pela estimulação dos nervos terminais das cavidades bucal e nasal [12].

A análise sensorial enfoca as características sensoriais de um produto e determina qual é o preferido e/ou melhor, aceitável por um determinado público alvo, em função de suas características. Os testes afetivos também chamados de testes de consumidor podem ser classificados em duas categorias: aceitabilidade e preferência. O primeiro tem o objetivo de avaliar o grau com que consumidores gostam ou desgostam de um determinado produto e o segundo objetiva avaliar a preferência do consumidor quando ele compra dois ou mais produtos entre si [4, 11, 12, 20, 24].
Os testes afetivos são usados para avaliar a preferência e/ou aceitação de produtos. Geralmente um grande número de julgadores é requerido para essas avaliações [11]. Os julgadores não são treinados, mas são selecionados para representar uma população alvo [24]. Os testes afetivos são uma ferramenta importante, de forma que acessam diretamente a opinião do consumidor já estabelecido ou potencial de um produto, sobre características específicas ou idéias sobre o produto, por isso são também chamados de testes de consumidor [12].

As principais aplicações dos testes afetivos são a manutenção da qualidade do produto, otimização de produtos e/ou processos e desenvolvimento de novos produtos. A escala hedônica é usada para medir o nível de preferência de produtos por uma população e relata os estados agradáveis e desagradáveis no organismo [11, 12, 24].

O processamento por extrusão termoplástica utilizando torta de amêndoa de castanha-do-brasil adicionada de farinha de mandioca gerou produtos do tipo cereais matinais nos sabores doce, natural e salgado, prontos para o consumo, ricos em carboidratos, proteínas, fibras e selênio, devido à presença destes constituintes no ingrediente básico, a torta de amêndoa de castanha-do-brasil [21, 22].

O presente trabalho teve o objetivo de avaliar a aceitabilidade de cereais matinais extrusados, formulados com torta de amêndoa de castanha-do-brasil e farinha de mandioca nos sabores doce, natural e salgado, em função do tempo de armazenagem.

\section{2 - MATERIAL E MÉTODOS}

\section{1 - Processamento de cereais matinais}

Os cereais extrusados foram processados a partir de dados obtidos do planejamento experimental fatorial completo composto central $2^{3}[2,21]$ que definiu as faixas otimizadas de formulação da mistura e condições ao processo de extrusão. Foram formulados os cereais utilizando-se: $60 \%$ de torta de amêndoa de castanha-do-brasil semidesengordurada e $40 \%$ de farinha de mandioca, contendo $21 \%$ de umidade e granulometria da mistura com $0,25 \mathrm{~mm}$ de diâmetro. $\mathrm{O}$ processamento foi realizado em extrusor monorrosca nas seguintes condições: taxa de compressão da rosca 3:1; velocidade de $175 \mathrm{rpm}$; taxa de alimentação 80 gramas por minutos; temperatura de $150{ }^{\circ} \mathrm{C}$ na $3^{\mathrm{a}}$ zona do canhão; formatação do produto com matriz circular de $2,0 \mathrm{~mm}$ de diâmetro; no Laboratório de Cereais do Departamento de Tecnologia de Alimentos da Faculdade de Engenharia de Alimentos da Universidade Estadual de Campinas - DTA/ FEA/UNICAMP.

Para obtenção dos produtos extrusados doce e salgado, foi adicionado, após a extrusão, xarope de sacarose a $20 \%$ e salmoura a $5 \% \mathrm{NaCl}$, respectivamente, nesta ordem. Os cereais foram desidratados em estufa a $60{ }^{\circ} \mathrm{C}$ por 12 horas e embalados em filmes flexíveis multicamadas aluminizado termo-soldável. 


\section{2 - Método sensorial}

Os testes de aceitação dos cereais matinais doces, natural e salgado foram realizados no Laboratório de Análise Sensorial do DTA/FEA/UNICAMP, utilizando-se cabines individuais, iluminadas com luz vermelha, para mascarar qualquer efeito de aparência dos produtos.

As amostras foram servidas de forma balanceada, em pratos de fundo preto, codificando-se cada uma com números de três dígitos. Para avaliar os três cereais, a partir do tempo zero (após o processamento) e a cada 30 dias de armazenagem, até o sexto mês, foi recrutado um painel sensorial constituído por 40 consumidores de ambos os sexos pertencentes à academia da FEA/UNICAMP, que participou de todos os meses da pesquisa.

Uma amostra de cereal matinal extrusado comercial, formulada à base de farelo de trigo, sabor levemente doce, adquirida no comércio local de Campinas-SP, foi avaliada em relação aos mesmos atributos, apenas no tempo zero (por não ter sido possível obter maior quantidade de produto da mesma marca e lote no mercado), seguindo as mesmas condições reportadas, visando comparação com os resultados dos cereais matinais extrusados de castanha-do-brasil com mandioca processados.

Para as avaliações dos atributos aceitação global, sabor e crocância dos produtos extrusados, foi utilizada a escala hedônica estruturada de 9 pontos [16], na qual 9 representava a nota máxima "adorei” e 1, a nota mínima "detestei".

A escala hedônica afetiva mede o gostar ou desgostar de um alimento. A avaliação da escala hedônica é convertida em escores numéricos e analisada estatisticamente para determinar a diferença no grau de preferência entre amostras.

Para o atributo intenção de compra, foi aplicada a escala estruturada de 5 pontos, na qual 5 representava a nota máxima "certamente compraria" e 1 representava a nota mínima "certamente não compraria”, a 40 provadores não treinados, durante a vida-de-prateleira (mensal durante seis meses) dos cereais extrusados, (Ficha 1), empregando os procedimentos descritos para análise sensorial [4, 12, 20, 24].

FICHA 1 - Avaliação sensorial de cereal matinal de torta de amêndoa de castanha-do-brasil com farinha de mandioca extrusado, sabores doce, natural e salgado e de um cereal matinal comercial extrusado.

\begin{tabular}{|c|c|}
\hline $\begin{array}{l}\text { PROVADOR N }{ }^{\circ} \\
\text { Nome: }\end{array}$ & Data: ___ \\
\hline
\end{tabular}

1. Você está recebendo 03 amostras codificadas de um cereal matinal extrusado formulado com torta de amêndoa de castanha-do-brasil e farinha de mandioca. Por favor, prove-as e avalie de forma global, utilizando a escala abaixo, o quanto você gostou ou desgostou:

9. adorei

8. gostei muito

7. gostei moderadamente

6. gostei ligeiramente

5. nem gostei/ nem desgostei

4. desgostei ligeiramente

3. desgostei moderadamente

2. desgostei muito

1. detestei

Código da Amostra $\quad$ Nota Valor $\quad$ Comentário

123

231

312

2. Agora, utilizando a mesma escala cima, prove as amostras novamente e avalie o quanto você gostou ou desgostou quanto ao sabor. Código da Amostra Nota Valor Comentário 132

231

3. Novamente, utilizando a mesma escala cima, prove as amostras outra vez e avalie o quanto você gostou ou desgostou quanto à crocância. Código da Amostra Nota Valor Comentário

123

231

312

4. Com base na sua opinião sobre estas amostras, indique na escala abaixo, sua atitude, se você encontrasse cada uma das amostras à venda. Se eu encontrasse este produto à venda eu:

5. certamente compraria

4. possivelmente compraria

3. talvez comprasse/ talvez não comprasse

2. possivelmente não compraria

1. certamente não compraria

Código da Amostra

Nota Valor

Comentário

123

231

312 


\section{3 - Análise estatística}

Os resultados obtidos foram submetidos a tratamentos estatísticos, utilizando-se o Programa Statistic for Windows versão 5.0 [23] aplicando-se o teste de Tukey para avaliar e comparar diferenças entre as médias $(\mathrm{p} \leq 0,05)$ [6].

\section{3 - RESULTADOS E DISCUSSÃO}

Os resultados da avaliação sensorial dos cereais matinais de castanha-do-brasil com mandioca durante a shelf-life de 6 meses e do cereal matinal comercial extrusado no tempo zero estão apresentados nas Tabelas 1, 2, 3,4.

TABELA 1 - Comparação de médias das notas de aceitação global dos cereais extrusados sabores doce, natural e salgado no período de seis meses de estocagem e do cereal matinal comercial extrusado no tempo zero.

\begin{tabular}{ccccc}
\hline \multicolumn{5}{c}{ Médias das notas para aceitação global dos cereais extrusados } \\
\hline $\begin{array}{c}\text { Tempo de estocagem } \\
\text { (meses) }\end{array}$ & $\begin{array}{c}\text { Cereal } \\
\text { doce }\end{array}$ & $\begin{array}{c}\text { Cereal } \\
\text { Natural }\end{array}$ & $\begin{array}{c}\text { Cereal } \\
\text { Salgado }\end{array}$ & $\begin{array}{c}\text { Cereal } \\
\text { Comercial }\end{array}$ \\
\hline 0 & $7,75 \mathrm{ab}$ & $7,57 \mathrm{ab}$ & $7,25 \mathrm{ab}$ & $5,7 \mathrm{c}$ \\
1 & $7,68 \mathrm{ab}$ & $7,38 \mathrm{ab}$ & $7,13 \mathrm{~b}$ & - \\
2 & $8,05 \mathrm{a}$ & $7,43 \mathrm{ab}$ & $7,57 \mathrm{ab}$ & - \\
3 & $7,9 \mathrm{ab}$ & $7,68 \mathrm{ab}$ & $7,57 \mathrm{ab}$ & - \\
4 & $7,65 \mathrm{ab}$ & $7,53 \mathrm{ab}$ & $7,63 \mathrm{ab}$ & - \\
5 & $7,82 \mathrm{ab}$ & $7,28 \mathrm{ab}$ & $7,35 \mathrm{ab}$ & - \\
6 & $7,65 \mathrm{ab}$ & $7,30 \mathrm{ab}$ & $7,35 \mathrm{ab}$ & - \\
\hline
\end{tabular}

Médias com letras iguais nas mesmas linhas e colunas não diferem significativamente entre si $(p \leq 0,05)$ pelo teste de Tukey.

A Tabela 1 apresenta os resultados das médias das notas de aceitação global dos cereais avaliados, sendo que o cereal matinal doce apresentou médias de aceitação global superiores aos demais, porém com diferença significativa $(p \leq 0,05)$ deste de sabor doce, apenas no tempo de 2 meses, em relação ao tempo de um mês do salgado e ao tempo zero do comercial. Nos demais tempos não houve diferença significativa.

Entretanto, pelo mesmo teste, os três produtos contendo castanha-do-brasil foram diferentes $(\mathrm{p} \leq 0,05)$ do cereal matinal comercial no tempo zero, alcançando médias de notas superiores, denotando que tiveram mais aceitabilidade que os disponibilizados no comércio para o consumo.

TABELA 2 - Comparação de médias das notas de sabor dos cereais extrusados doce, natural e salgado nos períodos de estocagem e do cereal matinal comercial extrusado no tempo zero.

\begin{tabular}{ccccc}
\hline \multicolumn{5}{c}{ Médias das notas de sabor dos cereais extrusados } \\
\hline $\begin{array}{c}\text { Tempo de estocagem } \\
\text { (meses) }\end{array}$ & $\begin{array}{c}\text { Cereal } \\
\text { doce }\end{array}$ & $\begin{array}{c}\text { Cereal } \\
\text { Natural }\end{array}$ & $\begin{array}{c}\text { Cereal } \\
\text { Salgado }\end{array}$ & $\begin{array}{c}\text { Cereal } \\
\text { Comercial }\end{array}$ \\
\hline 0 & $7,88 \mathrm{ab}$ & $7,57 \mathrm{ab}$ & $7,22 \mathrm{a}$ & $5,75 \mathrm{c}$ \\
1 & $7,78 \mathrm{ab}$ & $7,47 \mathrm{ab}$ & $7,28 \mathrm{a}$ & - \\
2 & $8,13 \mathrm{ab}$ & $7,47 \mathrm{ab}$ & $7,53 \mathrm{ab}$ & - \\
3 & $8,05 \mathrm{ab}$ & $7,70 \mathrm{ab}$ & $7,57 \mathrm{ab}$ & - \\
4 & $7,88 \mathrm{ab}$ & $7,35 \mathrm{ab}$ & $7,65 \mathrm{ab}$ & - \\
5 & $8,05 \mathrm{ab}$ & $7,25 \mathrm{a}$ & $7,43 \mathrm{ab}$ & - \\
6 & $8,00 \mathrm{ab}$ & $7,63 \mathrm{ab}$ & $7,90 \mathrm{ab}$ & - \\
\hline
\end{tabular}

Médias com letras iguais nas mesmas linhas e colunas não diferem significativamente entre si $(p \leq 0,05)$ pelo teste de Tukey.
Os resultados apresentados na Tabela 2 mostram que, em relação ao sabor, os cereais de castanha com mandioca foram diferentes significativamente $(p \leq 0,05)$ do cereal matinal comercial, cujos valores das médias variam de 7,22 a 8,13 , contra 5,75 do cereal comercial. Porém os cereais de sabor doce tiveram maiores valores nas médias, porém não houve diferença significativa na maioria dos tempos de armazenagem. Assim, as notas atribuídas aos três produtos extrusados de castanha com mandioca revelaram-se como mais agradáveis no sabor.

TABELA 3 - Comparação de médias das notas de crocância dos cereais extrusados doce, natural e salgado no período de estocagem e do cereal matinal comercial extrusado no tempo zero.

\begin{tabular}{ccccc}
\hline \multicolumn{5}{c}{ Médias das notas de crocância dos cereais extrusados } \\
\hline $\begin{array}{c}\text { Tempo de estocagem } \\
\text { (meses) }\end{array}$ & $\begin{array}{c}\text { Cereal } \\
\text { doce }\end{array}$ & $\begin{array}{c}\text { Cereal } \\
\text { Natural }\end{array}$ & $\begin{array}{c}\text { Cereal } \\
\text { Salgado }\end{array}$ & $\begin{array}{c}\text { Cereal } \\
\text { Comercial }\end{array}$ \\
\hline 0 & $8,02 \mathrm{ab}$ & $7,57 \mathrm{ab}$ & $7,55 \mathrm{ab}$ & $6,62 \mathrm{c}$ \\
1 & $7,85 \mathrm{ab}$ & $7,43 \mathrm{ab}$ & $7,65 \mathrm{ab}$ & - \\
2 & $8,10 \mathrm{a}$ & $7,82 \mathrm{ab}$ & $7,85 \mathrm{ab}$ & - \\
3 & $8,07 \mathrm{a}$ & $7,90 \mathrm{ab}$ & $7,75 \mathrm{ab}$ & - \\
4 & $7,95 \mathrm{ab}$ & $7,85 \mathrm{ab}$ & $7,95 \mathrm{ab}$ & - \\
5 & $7,82 \mathrm{ab}$ & $7,60 \mathrm{ab}$ & $7,85 \mathrm{ab}$ & - \\
6 & $7,72 \mathrm{ab}$ & $7,22 \mathrm{~b}$ & $7,15 \mathrm{~b}$ & - \\
\hline
\end{tabular}

Médias com letras iguais nas mesmas linhas e colunas não diferem significativamente entre si $(p \leq 0,05)$ pelo teste de Tukey.

Em relação ao atributo crocância, os dados da Tabela 3 mostram que houve diferença significativa $(\mathrm{p} \leq 0,05)$ entre os cereais de castanha com mandioca e o comercial, de forma que estes apresentaram as médias das notas maiores que o comercial. Porém o cereal doce diferiu nos tempos 2 e 3 de armazenagem dos cereais natural e salgado no tempo de 6 meses, cujas médias das notas do cereal doce foram 8,10 e 8,07, nos respectivos tempos.

HOUGH et al. [9] observaram que, quando outros atributos agradam ao consumidor, mas a textura ou a crocância não agradam, a rejeição ao alimento é imediata. Um produto sem crocância, nem mesmo o adequado sabor pode aprová-lo. A maioria de produtos com conteúdo baixo de umidade, panificado ou extrusado, tais como cereais matinais, biscoitos, wafers, biscoitos e lanches têm uma textura crocante. Se o conteúdo de umidade desses produtos aumentar, devido à sorção de água da atmosfera ou transporte em massa de componentes vizinhos, resulta em umedecimento e texturas moles, ou seja, perda de crocância [17]. Produtos crocantes têm uma estrutura celular de baixa densidade, são quebradiços, friáveis e geram alto barulho quando quebrado. Dessa forma, a crocância está associada com contrastes texturais agradáveis de frescor e qualidade, sua perda é a grande causa da rejeição do consumidor e evitar essa perda é o maior interesse da indústria de alimentos.

A curva característica de crocância apresenta vários picos, referentes a várias fraturas antes da ruptura, que é um dos indicativos de produtos crocantes. Outro parâmetro importante na característica de textura é a força necessária para romper o produto, o que indica sua dureza [8]. 
A vida de prateleira dos alimentos está diretamente relacionada com a eficiência da embalagem, de suas propriedades barreira, dos requerimentos de proteção que desempenha e, mais especificamente, da qualidade versus custo total do sistema. [5]. O sistema de embalagem utilizado neste experimento, o filme flexível multicamada aluminizado, com propriedades barreiras a gases, luz e umidade contribuíram de forma relevante para manter as características sensoriais e aceitação dos cereais.

TABELA 4 - Comparação de médias das notas de Intenção de compra dos cereais extrusados doce, natural e salgado no período de estocagem e do cereal matinal comercial extrusado no tempo zero.

\begin{tabular}{|c|c|c|c|c|}
\hline \multicolumn{5}{|c|}{ Médias das notas de intenção de compra dos cereais extrusados } \\
\hline $\begin{array}{c}\text { Tempo de estocagem } \\
\text { (meses) }\end{array}$ & $\begin{array}{c}\text { Cereal } \\
\text { doce }\end{array}$ & $\begin{array}{l}\text { Cereal } \\
\text { Natural }\end{array}$ & $\begin{array}{l}\text { Cereal } \\
\text { Salgado }\end{array}$ & $\begin{array}{c}\text { Cereal } \\
\text { Comercial }\end{array}$ \\
\hline 0 & $4,63 a b$ & $4,13 a b$ & $3,95 b$ & $3,02 \mathrm{c}$ \\
\hline 1 & $4,35 a b$ & $3,95 b$ & $3,90 \mathrm{~b}$ & - \\
\hline 2 & $4,65 a b$ & $4,07 a b$ & $4,25 a b$ & - \\
\hline 3 & $4,43 a b$ & $4,07 a b$ & $4,15 a b$ & - \\
\hline 4 & $4,50 a b$ & $4,07 a b$ & $4,22 a b$ & - \\
\hline 5 & $4,43 a b$ & $4,07 a b$ & $4,38 a b$ & - \\
\hline 6 & $4,40 a b$ & $4,10 a b$ & $3,92 b$ & - \\
\hline
\end{tabular}

Médias com letras iguais nas mesmas linhas e colunas não diferem significativamente entre si $(p \leq 0,05)$ pelo teste de Tukey.

Na Tabela 4, observa-se que as médias encontradas para os cereais de castanha com mandioca, referentes ao atributo Intenção de compra, foram diferentes significativamente $(\mathrm{p} \leq 0,05)$ da média encontrada para $o$ cereal matinal comercial extrusado, de forma que todos os cereais de castanha com mandioca alcançaram médias superiores ao valor 3,02 (Talvez comprasse/talvez não comprasse) atribuído para o cereal comercial. Na maior parte dos tempos de armazenagem, não houve diferença significativa ( $\mathrm{p} \leq 0,05$ ) pelo teste de Tukey, entre os cereais de castanha com mandioca. As que ocorreram foram nos tempos 1 para o sabor natural e 0, 1 e 6 para o sabor salgado. Essa diferença pode ter sido em decorrência da amostragem. Mesmo assim, os produtos extrusados com castanha-do-brasil e mandioca tiveram notas satisfatórias para intenção de compra significando atitude aceitável dos provadores.

Baseado nestes resultados observa-se, em relação a todos os atributos sensoriais avaliados, que as amostras de cereais matinais extrusados de castanha-do-brasil com mandioca, alcançaram médias de aceitação global, sabor e crocância entre os valores das escalas 7 e 8 - de "gostei moderadamente" a "gostei muito", significativamente $(p \leq 0,05)$ diferentes e superiores às médias dos mesmos atributos avaliados para o cereal matinal extrusado comercial, cujo valores foram: 5,7 para aceitação global, 5,75 para sabor e 6,62 para crocância, equivalentes a "nem gostei/nem desgostei" e "gostei ligeiramente", respectivamente, podendo justificar o processamento e oferta destes tipos de cereais contendo castanha-do-brasil com mandioca no mercado consumidor.

\section{4 - CONCLUSÃO}

Os cereais matinais de torta de amêndoa de castanhado-brasil com mandioca extrusados sabores doce, natural e salgado apresentam as médias das notas maiores do que o cereal matinal comercial extrusado existente no mercado; significando melhores características sensoriais em relação à aceitação global, sabor, crocância e intenção de compra.

O cereal extrusado de torta de amêndoa de castanha-dobrasil com mandioca de sabor doce recebeu maiores notas para todos os atributos avaliados que o natural e salgado, porém sem diferenças significativas;

Não foram detectadas alterações nos atributos sensoriais que comprometessem a aceitabilidade dos produtos, durante o tempo de vida-de-prateleira de seis meses, sendo satisfatória a sua aceitação.

\section{5 - REFERÊNCIAS BIBLIOGRÁFICAS}

[1] ALVAREZ, M. D. et al. An reengineering method to evaluate the crisp texture of fruit and vegetables. Journal of texture studies, v. 31, n. 4, p. 457-473, 2000.

[2] BARROS NETO, B. DE; SCARMINIO, I. S.; BRUNS, R. E. Planejamento e otimização de experimentos. 2. ed. Campinas: Editora da UNICAMP, 1995. 299 p.

[3] BHATTACHARYA, M.; HANNA, M. A.; KAUFMAN, R. E. Textural properties of extruded plant protein blends. Journal of Food Science, v. 51, n. 4, p. 988-993, JulyAug. 1986.

[4] DAMÁSIO, M. H.; SILVA, M. A. A. P. Curso de treinamento em análise sensorial. Apostila. Campinas: Fundação Tropical de Tecnologia "André Tosello", 1996.

[5] FARIA, J. de A. F. Packaging and shelf life of extruded products. In: CHANG, Y. K.; WANG, S. S. Advances in extrusion technology - Proceedings of the International Symposium On Animal \& Aquaculture Feedstuffs by Extrusion Technology, Águas de Lindóia: Technomic Publishing Co. Inc., p. 321-327, 1998.

[6] GOMES, F. P. Curso de estatística experimental. 13. ed. Piracicaba: Nobel, 1990. 467 p.

[7] HASLER, C. M. A new look at an ancient concept. Chemistry Industry, v. 2, p. 84-89, 1998.

[8] HOFSETZ, K. et al. Caracterização sensorial e instrumental de crocância de maçã e abacaxi comerciais liofilizados. In: XVIII CONGRESSO BRASILEIRO DE CIÊNCIA E TECNOLOGIA DE ALIMENTOS, 2002, Porto Alegre. Anais... Porto Alegre, ago, 2002. 1 CD ROM.

[9] HOUGH, G. et al. O. Sensory texture of commercial biscuits as a function of water activity. Journal of texture studies, v. 32, n. 1. p. 57-74. Apr, 2001.

[10] LIN, S.; HSIEH, E. F. Extrusion process parameters, sensory characteristics, and structural properties of a high moisture soy protein meat analog. Journal of Food Science, v. 67, n. 3, p. 1066-1072, Apr, 2002.

[11] MACFIE, H. J.; THOMSON, D. M. H. Measurement of food preferences. Glasgow: Blackie Academic \& Professional, 1994. 310 p.

[12] MEIlGAARD, M.; CIVIlle, G. V.; CARR, B. T. Sensory evaluation techniques. 2.ed. Flórida: CRC Press, 1991. $354 \mathrm{p}$. 
[13] OLIVEIRA, N. M. B. de Dietoterapia na prática médica. Rio de Janeiro: Cultura médica Ltda., 1975. 35 p.

[14] ORAM, N. Texture and chemical feeling descriptors that 6-11 year olds and adults associate with food in the mouth. Journal of texture studies, v. 29, n. 2, p. 185-197, May 1998.

[15] PAYNE, T. J. Snack ideas from fruits to nuts: Cultivated blueberries and California walnuts. Cereal Foods World, v. 45, n. 10, p. 453-456 Oct, 2000.

[16] PERYAM, D. R.; GIRARDOT, N. Advanced taste - method. Food Eng, v. 24, p. 58-61. 1952.

[17] ROUDAUT, G.; DACREMONT, C.; MESTRE, M. L. Influence of water on the crispness of cereal-based foods: acoustic, mechanical, and sensory studies. Journal of texture studies, v. 29, n. 2. p. 199-213, May, 1998.

[18] SARDAGNA, L. D. et al. Desenvolvimento de um cereal matinal fortificado e adicionado de fibra solúvel. In: XVIII CONGRESSO BRASILEIRO DE CIÊNCIA E TECNOLOGIA DE ALIMENTOS, 2002, Porto Alegre. Anais... ago. 2002. 1 CD.

[19] SCHOSSLER, F.; SCHNEIDER, R. C. S. Formulações caseiras de barras de cereais. In: XVIII CONGRESSO BRASILEIRO DE CIÊNCIA E TECNOLOGIA DE ALIMENTOS, 2002, Porto Alegre. Anais... Porto Alegre, ago. 2002. $1 \mathrm{CD}$.

[20] SILVA, M. A. A. P. Métodos de avaliação sensorial de alimentos. Apostila: Escola de Extensão da UNICAMP. 1997. $71 \mathrm{p}$.
[21] SOUZA, M. L. de. Processamento de cereais matinais extrusados de castanha-do-brasil com mandioca. 2003. 191 f. Tese (Doutorado em Tecnologia de Alimentos) - Faculdade de Engenharia de Alimentos da Universidade Estadual de Campinas, UNICAMP, Campinas, São Paulo, 2003.

[22] . Processamento de amêndoa e torta de castanha-do-brasil e farinha de mandioca: parâmetros de qualidade. Ciência e Tecnologia de Alimentos, v. 24, n. 1, p. 120-128, 2004.

[23] STATISTIC for Windows. Versão 5.0. Copyright Stat Soft, Inc., Tulsa, USA, 1995.

[24] STONE, H.; SIDEL, J. L. Sensory evaluation practices. Flórida-USA: Academic Press, Inc. 1985. 311 p.

[25] SUNKNARK, K. et al. Stability of tocopherol and retinyl palmitate in snack extrudates. Journal of Food Science, v. 66, n. 6, p. 897-902, Aug, 2001.

[26] TAKEUCHI, K. P.; SABADINI, E.; CUNHA, R. L. da. Análise das propriedades mecânicas de cereais matinais com diferentes fontes de amido durante o processo de absorção de leite. Ciênc. Tecnol. Aliment., v. 25, n. 1, p. $78-85,2005.1$ CD ROM.

\section{6 - AGRADECIMENTOS}

À Fundação de Amparo à Pesquisa do Estado de São Paulo - FAPESP -e ao Conselho Nacional de Desenvolvimento Cientifico Tecnológico - CNPq -, pelo auxílio financeiro ao projeto e bolsa concedidos. 